\title{
Effect of Carbon Emission and Shelf-Life on Random Emission and Random Price Dependent Demand of a Perishable Product in Interval Environment
}

\section{Nabajyoti Bhattacharjee}

Assam University - Dargakona Campus: Assam University

Nabendu Sen ( $\sim$ nsen08@yahoo.com )

Assam University - Dargakona Campus: Assam University https://orcid.org/0000-0001-7900-161X

\section{Research Article}

Keywords: Inventory model, Carbon emission, Shelf-life, Green investment, Preservation cost, Probabilistic demand, Deterministic demand, Particle Swarm Optimization with Constriction Factor, Weighted Particle Swarm Optimization, Genetic Algorithm

Posted Date: May 24th, 2021

DOl: https://doi.org/10.21203/rs.3.rs-474629/v1

License: (c) (1) This work is licensed under a Creative Commons Attribution 4.0 International License.

Read Full License 
Effect of Carbon Emission and Shelf-Life on Random Emission and Random Price Dependent Demand of a Perishable Product in Interval Environment

\author{
Nabajyoti Bhattacharjee ${ }^{1}$ and Nabendu Sen $^{2 *}$ \\ ${ }^{1} \underline{\text { nbgg2017@gmail.com and }{ }^{2} \text { nsen08@yahoo.com }}$ \\ ${ }^{1}$ Department of Mathematics, Assam University, Silchar, India \\ ${ }^{2}$ Department of Mathematics, Assam University, Silchar, India
}

Corresponding Author: Nabendu Sen

Email of Corresponding Author: nsen08@yahoo.com

\begin{abstract}
An inventory of suppliers dealing with supply of raw materials from the natural resources like sugarcane, beetroot, vegetable scraps etc. need to choose the product for supply to the production industries with a great consciousness due to their finite shelf-life and carbon emission property. A product with small shelf-life and carrying the burden of carbon tax need to be sold quickly so that overall profit earn can be maximize in such a situation. Further the situation deteriorates when the selling price of a product is affected by the carbon emission and its absolute value reduces with time. There we need a formal mathematical design that can include all these issues of price and carbon tax so that the supplier can select the best product for sale. In this paper we develop and inventory model to investigate the earnings made by the supplier, selling the product with price- and stock- dependent demand and study the effect of carbon emission and shelf-life. Further we obtain the optimal preservation cost and green investment to reduce the deterioration and carbon emission. We study the model under different cases; deterministic demand, probabilistic demand with random emission and probabilistic demand with random price. We perform the sensitivity analysis.
\end{abstract}

Key Words: Inventory model, Carbon emission, Shelf-life, Green investment, Preservation cost, Probabilistic demand, Deterministic demand, Particle Swarm Optimization with Constriction Factor, Weighted Particle Swarm Optimization, Genetic Algorithm 


\title{
Effect of Carbon Emission and Shelf-Life on Random Emission and Random Price Dependent Demand of a Perishable Product in Interval Environment
}

\begin{abstract}
An inventory of suppliers dealing with supply of raw materials from the natural resources like sugarcane, beetroot, vegetable scraps etc. need to choose the product for supply to the production industries with a great consciousness due to their finite shelf-life and carbon emission property. A product with small shelf-life and carrying the burden of carbon tax need to be sold quickly so that overall profit earn can be maximize in such a situation. Further the situation deteriorates when the selling price of a product is affected by the carbon emission and its absolute value reduces with time. There we need a formal mathematical design that can include all these issues of price and carbon tax so that the supplier can select the best product for sale. In this paper we develop and inventory model to investigate the earnings made by the supplier, selling the product with price- and stock- dependent demand and study the effect of carbon emission and shelf-life. Further we obtain the optimal preservation cost and green investment to reduce the deterioration and carbon emission. We study the model under different cases; deterministic demand, probabilistic demand with random emission and probabilistic demand with random price. We perform the sensitivity analysis.
\end{abstract}

Key Words: Inventory model, Carbon emission, Shelf-life, Green investment, Preservation cost, Probabilistic demand, Deterministic demand, Particle Swarm Optimization with Constriction Factor, Weighted Particle Swarm Optimization, Genetic Algorithm

\section{Introduction}

In the production industries of sugar and ethanol, the use of natural resources as a raw material in a common practice. However, exploiting natural resources like sugarcane, Woodstock, vegetable scrap etc. can increase the risk of carbon emission in the environment due to fast rate of deterioration. Further, over utilization of natural resources can cause natural disasters and therefore a controlled supply of these products to the production industries is important in order to earn a good profit and simultaneously minimizing the carbon tax.Apart from carbon emission the products stated above have a small shelf-life so the supplier must sale the product as early as possible. Incorporation and exploitation of green technologies and modern preservation techniques can reduce both carbon tax and deterioration cost. Inventory modelling is an active are of research since decades. Recently the research work on the application and analysis of carbon footprints and its effect on the demand of a product is an interesting topic for the researchers. Saha et. al (2021), proposed a supply chain model to study the competition on green products retailing. A study on green policies is proposed by Dutta et. al (2019). Ritha and Poongidisathiya (2018) proposed a green inventory model to minimize the total cost of the system and optimize the ordering quantity of the carbon sensitive products under green policies.Hovelaque and Bironneau (2015) proposedan EOQ model with emission dependent demand and carbon constraint. De-la-Cruz-Marquez et. al (2021), propose an inventory model with price dependent demand and considering carbon emission with imperfect quality. For more research on EOQ inventory model under carbon emission we referChristata and Daryanto (2020).Dutta (2017), made an extensive research on effect of green investment on production inventory with carbon emission under bounded production limit the research illustrate that, carbon emission cost has positive effect on 
environment and negative effect on GDP.A three-stage dynamic game model is developed by Tang et. al (2020) and proposed an inventory model to optimize sustainable transportation cost, wholesale price and a carbon tax policy. An inventory model for perishable items is proposed by Macias-Lopez et. al (2021) with price, stock and time dependent demand with quadratic holding cost, the demand functions considered in the model are linear, iso-elastic, exponential, logit, logarithmic and polynomial function.Carbon reduction and price dependent demand is investigated by Lu et. al (2020) for the deteriorating items under game theory methodology. A sustainable inventory modelling is developed by Sarkar et. al (2018) with multi-trade-credit-period and backordering.

Stochastic inventory and supply chain models were developed to study a parameter under different probabilistic distributions such as uniform, triangular, beta, gamma etc. Most of the stochastic model is developed by considering probabilistic deterioration we refer the following research work in this direction Palanivel et al. (2015) and Sarkar (2013), Sarkar \& Sarkar (2013) and Singh et al. (2013).

For inventory models assuming the carbon emission in the demand, supply chain and as a constraint we refer Allabadi et al. (2018), Arkin \&Jammernegg (2014) and Benjaafar and Daskin (2013).

\section{Description of Problem}

In demand and supply chain of perishable raw materials to produce biofuel, ethanol, sugar, paper etc. the vendor faces to major problem related to deterioration and carbon emission. A perishable product has a short shelf-life and must be distributed before the sell-by period. Further the production industries prefer the raw materials whose rate of carbon emission is low, therefore the demand of the raw materials depends on both shelf-life and rate of carbon emission. In our present paper, we made an attempt to develop an inventory model to study the effect of shelf-life and carbon emission on the demand of the product. The different cases that we study under given inventory model are as follows;

a) To analyse the profit earns under random emission.

b) To analyse the profit earns under probabilistic selling price.

c) To analyse the profit under variable shelf-life and rate of carbon emission

d) To analyse the profit under different pattern of carbon emission

\section{Methodology}

In order to solve the model for optimization, first we convert the profit function from crisp environment to interval environment. Then solve the model in interval environment using three forms of particle swarm optimization algorithm, that is, Weighted PSO, Constriction PSO and Quantum PSO and the solution is accepted after statistical verification. We employ linear differential equation to develop the inventory model. We perform sensitivity analysis of the parameters.

4. Notation

\begin{tabular}{clll}
\hline 1) & Symbol & Unit & Meaning \\
\hline $\boldsymbol{I}_{\mathbf{0}}$ & Units & Maximum inventory level \\
$\boldsymbol{I}(\boldsymbol{t})$ & Units/ unit time & Inventory level at any time $t$ \\
$\boldsymbol{\theta}$ & Constant $(0<\theta<1)$ & Rate of deterioration \\
$\boldsymbol{\beta}$ & $\$$ & Preservation cost \\
$\boldsymbol{I}_{\boldsymbol{g}}$ & Constant, $0<\gamma \leq 1$ & Green investment \\
$\boldsymbol{\gamma}$ & Unit time & Rate of carbon emission \\
$\boldsymbol{T}$ & Unit/unit time & Planning horizon \\
$\boldsymbol{R}$ & \$/unit & Rate of replenishment \\
$\boldsymbol{p}$ & \$/unit & Selling price \\
$\boldsymbol{c} \boldsymbol{e}$ & \$/unit & Carbon emission cost \\
$\boldsymbol{c}$ & \$/unit & Cost of purchased item \\
$\boldsymbol{H}$ & Unit & Holding cost \\
$\boldsymbol{d}$ & Unit & Initial demand \\
$\boldsymbol{D}(\boldsymbol{t}, \boldsymbol{p}, \boldsymbol{\gamma})$ & Units & Demand function \\
$\boldsymbol{f}(\boldsymbol{\gamma})$ & Unit time & Amount of carbon emission \\
$\boldsymbol{\tau}$ & & Shelf-life \\
\hline
\end{tabular}

\section{Assumption}

- Lead time is zero

- The effect of carbon emission on the demand is defined as; 


$$
\rho(\gamma)=\frac{K}{f(\gamma)}
$$

Where $K \in(0,1)$ is the scaling factor that measures the effect of carbon emission on the demand of a product

- Demand function

$$
D(t, p, \gamma)=\frac{K[d+I(t)-\alpha p(t)]}{f(\gamma)}
$$

where $0<\alpha<1$ is the price sensitivity and $f(\gamma)$ is function of rate of carbon emission representing the pattern of carbon emission.

- The selling price is a function of time and it is defined as;

$$
p(t)=p\left(\frac{\tau-t}{\tau f(\gamma)}\right) \quad \forall t \in[0, T]
$$

- The rate of carbon emission $\gamma$ is random.

- The shelf-life $\tau$ is random

- Replenishment quantity is constant and instantaneous.

- Deterioration is a function of preservation cost and rate of carbon emission $\theta(\beta, \gamma)=$ $\theta\left(1-e^{-(f(\gamma)-a \beta)}\right)$ where, $0<a<1$ is the sensitivity of preservation cost

- Carbon emission cost in inventory is a function of green investment $c_{e}\left(\gamma, I_{g}\right)=$ $c_{e} e^{-\left(b I_{g}-f(\gamma)\right)}$, where $0<b<1$ is sensitivity of green investment

- Shortages are not allowed.

- Planning horizon is infinite and $T<\tau$.

\section{Model Formulation}

The differential equation representing the flow of material from the stock to the market is given by;

Subject to the condition $I(0)=I_{0}$

$$
\frac{d I}{d t}+\theta(\beta, \gamma) I=R-D(t, p, \gamma)
$$

The inventory level at any time $t$ is given by;

$$
\begin{aligned}
& I(t)=I_{0} e^{-t(\theta(\beta, \gamma)+\rho(\gamma))}+\left(\frac{R K+\alpha \rho^{2}(\gamma)-d \rho(\gamma) K}{K(\theta(\beta, \gamma)+\rho(\gamma))}-\frac{\alpha \rho^{2}(\gamma)}{\tau K(\theta(\beta, \gamma)+\rho(\gamma))^{2}}\right)\left(1-e^{-(\theta(\beta, \gamma)+\rho(\gamma)) t}\right) \\
& +\frac{\alpha \rho^{2}(\gamma) t}{\tau K(\theta(\beta, \gamma)+\rho(\gamma))}
\end{aligned}
$$

Holding cost:

$$
\begin{aligned}
H C=H\left\{\frac{I_{0}\left(1-e^{-(\theta(\beta, \gamma)+\rho(\gamma)) T}\right)}{\theta(\beta, \gamma)+\rho(\gamma)}\right. & \\
& +\left(\frac{R K+\alpha \rho^{2}(\gamma)-d \rho(\gamma) K}{K(\theta(\beta, \gamma)+\rho(\gamma))}-\frac{\alpha \rho^{2}(\gamma)}{\tau K(\theta(\beta, \gamma)+\rho(\gamma))^{2}}\right)\left(T+\frac{e^{-(\theta(\beta, \gamma)+\rho(\gamma)) T}-1}{\theta(\beta, \gamma)+f(\gamma)}\right) \\
& \left.+\frac{1}{2} \frac{\alpha \rho^{2}(\gamma) T^{2}}{\tau K(\theta(\beta, \gamma)+\rho(\gamma))}\right\}
\end{aligned}
$$

Deterioration cost:

$$
\begin{aligned}
D C=c \theta(\beta, \gamma)\{ & \frac{I_{0}\left(1-e^{-(\theta(\beta, \gamma)+\rho(\gamma)) T}\right)}{\theta(\beta, \gamma)+\rho(\gamma)} \\
& +\left(\frac{R K+\alpha \rho^{2}(\gamma)-d \rho(\gamma) K}{K(\theta(\beta, \gamma)+\rho(\gamma))}-\frac{\alpha \rho^{2}(\gamma)}{\tau K(\theta(\beta, \gamma)+\rho(\gamma))^{2}}\right)\left(T+\frac{e^{-(\theta(\beta, \gamma)+\rho(\gamma)) T}-1}{\theta(\beta, \gamma)+f(\gamma)}\right) \\
& \left.+\frac{1}{2} \frac{\alpha \rho^{2}(\gamma) T^{2}}{\tau K(\theta(\beta, \gamma)+\rho(\gamma))}\right\}
\end{aligned}
$$

Preservation cost:

Green investment:

$$
P C=\beta
$$

$$
G I=I_{g}
$$


Carbon emission cost:

$$
\begin{aligned}
C E C=c_{e}\left(I_{g}\right)\left\{\begin{array}{l}
I_{0}\left(1-e^{-(\theta(\beta, \gamma)+\rho(\gamma)) T}\right) \\
\theta(\beta, \gamma)+\rho(\gamma)
\end{array}\right. \\
\quad+\left(\frac{R K+\alpha \rho^{2}(\gamma)-d \rho(\gamma) K}{K(\theta(\beta, \gamma)+\rho(\gamma))}-\frac{\alpha \rho^{2}(\gamma)}{\tau K(\theta(\beta, \gamma)+\rho(\gamma))^{2}}\right)\left(T+\frac{e^{-(\theta(\beta, \gamma)+\rho(\gamma)) T}-1}{\theta(\beta, \gamma)+f(\gamma)}\right) \\
\left.\quad+\frac{\alpha \rho^{2}(\gamma) T^{2}}{2 K(\theta(\beta, \gamma)+\rho(\gamma))}\right\}
\end{aligned}
$$

Purchase cost:

$$
\operatorname{Pr} C=c\left(I_{o}+R T\right)
$$

Average total cost is given by;

$$
\begin{aligned}
A T C=c_{o}+H\{ & \frac{A T C=c_{o}+H C+D C+\alpha+I_{g}+C E C+\operatorname{Pr} C}{\theta(\beta, \gamma)+\rho(\gamma)} \\
& +\left(\frac{R K+\alpha \rho^{2}(\gamma)-d \rho(\gamma) K}{K(\theta(\beta, \gamma)+\rho(\gamma))}-\frac{\alpha \rho^{2}(\gamma)}{\tau K(\theta(\beta, \gamma)+\rho(\gamma))^{2}}\right)\left(T+\frac{e^{-(\theta(\beta, \gamma)+\rho(\gamma)) T}-1}{\theta(\beta, \gamma)+f(\gamma)}\right) \\
& \left.+\frac{1}{2} \frac{\alpha \rho^{2}(\gamma) T^{2}}{\tau K(\theta(\beta, \gamma)+\rho(\gamma))}\right\} \\
& +c \theta(\beta, \gamma)\left\{\frac{I_{0}\left(1-e^{-(\theta(\beta, \gamma)+\rho(\gamma)) T}\right)}{\theta(\beta, \gamma)+\rho(\gamma)}\right. \\
& +\left(\frac{R K+\alpha \rho^{2}(\gamma)-d \rho(\gamma) K}{K(\theta(\beta, \gamma)+\rho(\gamma))}-\frac{\alpha \rho^{2}(\gamma)}{\tau K(\theta(\beta, \gamma)+\rho(\gamma))^{2}}\right)\left(T+\frac{e^{-(\theta(\beta, \gamma)+\rho(\gamma)) T}-1}{\theta(\beta, \gamma)+f(\gamma)}\right) \\
& \left.+\frac{1}{2} \frac{\alpha \rho^{2}(\gamma) T^{2}}{\tau K(\theta(\beta, \gamma)+\rho(\gamma))}\right\}+\beta+I_{g} \\
& +c_{e}\left(I_{g}\right)\left\{\frac{I_{0}\left(1-e^{-(\theta(\beta, \gamma)+\rho(\gamma)) T}\right.}{\theta(\beta, \gamma)+\rho(\gamma)}\right. \\
& +\left(\frac{R K+\alpha \rho^{2}(\gamma)-d \rho(\gamma) K}{K(\theta(\beta, \gamma)+\rho(\gamma))}-\frac{\alpha \rho^{2}(\gamma)}{\tau K(\theta(\beta, \gamma)+\rho(\gamma))^{2}}\right)\left(T+\frac{e^{-(\theta(\beta, \gamma)+\rho(\gamma)) T}-1}{\theta(\beta, \gamma)+f(\gamma)}\right) \\
& \left.+\frac{\alpha \rho^{2}(\gamma) T^{2}}{2} \frac{1}{\tau K(\theta(\beta, \gamma)+\rho(\gamma))}\right\}+c\left(I_{o}+R T\right)
\end{aligned}
$$

Total revenue

$$
\begin{aligned}
T R=\frac{\rho(\gamma) p}{\tau f(\gamma)}[(d & \left.+\frac{R K+\alpha \rho^{2}(\gamma)-d \rho(\gamma) K}{K(\theta(\beta, \gamma)+\rho(\gamma))}-\frac{\alpha \rho^{2}(\gamma)}{\tau K(\theta(\beta, \gamma)+\rho(\gamma))^{2}}\right)\left(\tau T-\frac{T^{2}}{2}\right) \\
& +\frac{\alpha p\left(\tau^{3}-(\tau-T)^{3}\right)}{3 \tau f(\gamma)}+\frac{\alpha \rho^{2}(\gamma)\left(3 \tau T^{2}-2 T^{3}\right)}{6 \tau K(\theta(\beta, \gamma)+\rho(\gamma))} \\
& +\left(I_{0}-\frac{R K+\alpha \rho^{2}(\gamma)-d \rho(\gamma) K}{K(\theta(\beta, \gamma)+\rho(\gamma))}\right. \\
& \left.\left.+\frac{\alpha \rho^{2}(\gamma)}{\tau K(\theta(\beta, \gamma)+\rho(\gamma))^{2}}\right)\left(\frac{\tau-(\tau-T) e^{-(\theta(\beta, \gamma)+\rho(\gamma)) T}}{(\theta(\beta, \gamma)+\rho(\gamma))}-\frac{1-e^{-(\theta(\beta, \gamma)+\rho(\gamma)) T}}{(\theta(\beta, \gamma)+\rho(\gamma))^{2}}\right)\right]
\end{aligned}
$$

Average Profit

$$
A P=\frac{1}{T}[T R-A T C]
$$

Case I (Patterns of Carbon Emission): We consider three different patterns of carbon emission.

\begin{tabular}{|c|c|c|}
\hline Pattern & $\boldsymbol{\rho}(\boldsymbol{\gamma})$ & $\boldsymbol{f}(\boldsymbol{\gamma})$ \\
\hline I & $e^{-h \gamma}, h>0$ & $K e^{h \gamma}$ \\
\hline II & $1-\gamma$ & $\frac{K}{1-\gamma}$ \\
\hline III & $\sin \gamma$ & $K|\csc \gamma|$ \\
\hline
\end{tabular}


The decision variables under this case are;

Preservation cost $\beta$

Green investment $I_{g}$

Planning horizon $T$

Case II $(\operatorname{Random} \gamma)$ : The decision variable we consider are;

Preservation cost $\beta$

Green investment $I_{g}$

Planning horizon $T$

Case III (Random $\boldsymbol{p})$ : The decision variable we consider are;

Preservation $\operatorname{cost} \beta$

Green investment $I_{g}$

Planning horizon $T$

\section{Solution Procedure}

Let us convert the profit function from crisp environment to interval environment by converting cost parameter in interval form. The mathematical model formulated in interval form as;

Subject to constraint;

$$
\max \left[A P_{L}, A P_{R}\right]
$$

Where,

$$
A P_{L}<A P_{R}
$$

$$
\begin{aligned}
& A P_{R}=\frac{\rho(\gamma) p}{\tau f(\gamma)}\left[\left(d+\frac{R K+\alpha \rho^{2}(\gamma)-d \rho(\gamma) K}{K(\theta(\beta, \gamma)+\rho(\gamma))}-\frac{\alpha \rho^{2}(\gamma)}{\tau K(\theta(\beta, \gamma)+\rho(\gamma))^{2}}\right)\left(\tau T-\frac{T^{2}}{2}\right)\right. \\
& +\frac{\alpha p\left(\tau^{3}-(\tau-T)^{3}\right)}{3 \tau f(\gamma)}+\frac{\alpha \rho^{2}(\gamma)\left(3 \tau T^{2}-2 T^{3}\right)}{6 \tau K(\theta(\beta, \gamma)+\rho(\gamma))} \\
& +\left(I_{0}-\frac{R K+\alpha \rho^{2}(\gamma)-d \rho(\gamma) K}{K(\theta(\beta, \gamma)+\rho(\gamma))}\right. \\
& \left.\left.+\frac{\alpha \rho^{2}(\gamma)}{\tau K(\theta(\beta, \gamma)+\rho(\gamma))^{2}}\right)\left(\frac{\tau-(\tau-T) e^{-(\theta(\beta, \gamma)+\rho(\gamma)) T}}{(\theta(\beta, \gamma)+\rho(\gamma))}-\frac{1-e^{-(\theta(\beta, \gamma)+\rho(\gamma)) T}}{(\theta(\beta, \gamma)+\rho(\gamma))^{2}}\right)\right] \\
& -\left\{c_{O L}\right. \\
& +H_{L}\left\{\frac{I_{0}\left(1-e^{-(\theta(\beta, \gamma)+\rho(\gamma)) T}\right)}{\theta(\beta, \gamma)+\rho(\gamma)}\right. \\
& +\left(\frac{R K+\alpha \rho^{2}(\gamma)-d \rho(\gamma) K}{K(\theta(\beta, \gamma)+\rho(\gamma))}-\frac{\alpha \rho^{2}(\gamma)}{\tau K(\theta(\beta, \gamma)+\rho(\gamma))^{2}}\right)\left(T+\frac{e^{-(\theta(\beta, \gamma)+\rho(\gamma)) T}-1}{\theta(\beta, \gamma)+f(\gamma)}\right) \\
& \left.+\frac{1}{2} \frac{\alpha \rho^{2}(\gamma) T^{2}}{\tau K(\theta(\beta, \gamma)+\rho(\gamma))}\right\} \\
& +c_{L} \theta(\beta, \gamma)\left\{\frac{I_{0}\left(1-e^{-(\theta(\beta, \gamma)+\rho(\gamma)) T}\right)}{\theta(\beta, \gamma)+\rho(\gamma)}\right. \\
& +\left(\frac{R K+\alpha \rho^{2}(\gamma)-d \rho(\gamma) K}{K(\theta(\beta, \gamma)+\rho(\gamma))}-\frac{\alpha \rho^{2}(\gamma)}{\tau K(\theta(\beta, \gamma)+\rho(\gamma))^{2}}\right)\left(T+\frac{e^{-(\theta(\beta, \gamma)+\rho(\gamma)) T}-1}{\theta(\beta, \gamma)+f(\gamma)}\right) \\
& \left.+\frac{1}{2} \frac{\alpha \rho^{2}(\gamma) T^{2}}{\tau K(\theta(\beta, \gamma)+\rho(\gamma))}\right\}+\beta+I_{g} \\
& +c_{e L}\left(I_{g}\right)\left\{\frac{I_{0}\left(1-e^{-(\theta(\beta, \gamma)+\rho(\gamma)) T}\right)}{\theta(\beta, \gamma)+\rho(\gamma)}\right. \\
& +\left(\frac{R K+\alpha \rho^{2}(\gamma)-d \rho(\gamma) K}{K(\theta(\beta, \gamma)+\rho(\gamma))}-\frac{\alpha \rho^{2}(\gamma)}{\tau K(\theta(\beta, \gamma)+\rho(\gamma))^{2}}\right)\left(T+\frac{e^{-(\theta(\beta, \gamma)+\rho(\gamma)) T}-1}{\theta(\beta, \gamma)+f(\gamma)}\right) \\
& \left.\left.+\frac{1}{2} \frac{\alpha \rho^{2}(\gamma) T^{2}}{\tau K(\theta(\beta, \gamma)+\rho(\gamma))}\right\}+c_{L}\left(I_{o}+R T\right)\right\}
\end{aligned}
$$


And

$$
\begin{aligned}
& A P_{L}=\frac{\rho(\gamma) p}{\tau f(\gamma)}\left[\left(d+\frac{R K+\alpha \rho^{2}(\gamma)-d \rho(\gamma) K}{K(\theta(\beta, \gamma)+\rho(\gamma))}-\frac{\alpha \rho^{2}(\gamma)}{\tau K(\theta(\beta, \gamma)+\rho(\gamma))^{2}}\right)\left(\tau T-\frac{T^{2}}{2}\right)\right. \\
& +\frac{\alpha p\left(\tau^{3}-(\tau-T)^{3}\right)}{3 \tau f(\gamma)}+\frac{\alpha \rho^{2}(\gamma)\left(3 \tau T^{2}-2 T^{3}\right)}{6 \tau K(\theta(\beta, \gamma)+\rho(\gamma))} \\
& +\left(I_{0}-\frac{R K+\alpha \rho^{2}(\gamma)-d \rho(\gamma) K}{K(\theta(\beta, \gamma)+\rho(\gamma))}\right. \\
& \left.\left.+\frac{\alpha \rho^{2}(\gamma)}{\tau K(\theta(\beta, \gamma)+\rho(\gamma))^{2}}\right)\left(\frac{\tau-(\tau-T) e^{-(\theta(\beta, \gamma)+\rho(\gamma)) T}}{(\theta(\beta, \gamma)+\rho(\gamma))}-\frac{1-e^{-(\theta(\beta, \gamma)+\rho(\gamma)) T}}{(\theta(\beta, \gamma)+\rho(\gamma))^{2}}\right)\right] \\
& -\left\{c_{o R}\right. \\
& +H_{R}\left\{\frac{I_{0}\left(1-e^{-(\theta(\beta, \gamma)+\rho(\gamma)) T}\right)}{\theta(\beta, \gamma)+\rho(\gamma)}\right. \\
& +\left(\frac{R K+\alpha \rho^{2}(\gamma)-d \rho(\gamma) K}{K(\theta(\beta, \gamma)+\rho(\gamma))}-\frac{\alpha \rho^{2}(\gamma)}{\tau K(\theta(\beta, \gamma)+\rho(\gamma))^{2}}\right)\left(T+\frac{e^{-(\theta(\beta, \gamma)+\rho(\gamma)) T}-1}{\theta(\beta, \gamma)+f(\gamma)}\right) \\
& \left.+\frac{1}{2} \frac{\alpha \rho^{2}(\gamma) T^{2}}{\tau K(\theta(\beta, \gamma)+\rho(\gamma))}\right\} \\
& +c_{R} \theta(\beta, \gamma)\left\{\frac{I_{0}\left(1-e^{-(\theta(\beta, \gamma)+\rho(\gamma)) T}\right)}{\theta(\beta, \gamma)+\rho(\gamma)}\right. \\
& +\left(\frac{R K+\alpha \rho^{2}(\gamma)-d \rho(\gamma) K}{K(\theta(\beta, \gamma)+\rho(\gamma))}-\frac{\alpha \rho^{2}(\gamma)}{\tau K(\theta(\beta, \gamma)+\rho(\gamma))^{2}}\right)\left(T+\frac{e^{-(\theta(\beta, \gamma)+\rho(\gamma)) T}-1}{\theta(\beta, \gamma)+f(\gamma)}\right) \\
& \left.+\frac{1}{2} \frac{\alpha \rho^{2}(\gamma) T^{2}}{\tau K(\theta(\beta, \gamma)+\rho(\gamma))}\right\}+\beta+I_{g} \\
& +c_{e R}\left(I_{g}\right)\left\{\frac{I_{0}\left(1-e^{-(\theta(\beta, \gamma)+\rho(\gamma)) T}\right)}{\theta(\beta, \gamma)+\rho(\gamma)}\right. \\
& +\left(\frac{R K+\alpha \rho^{2}(\gamma)-d \rho(\gamma) K}{K(\theta(\beta, \gamma)+\rho(\gamma))}-\frac{\alpha \rho^{2}(\gamma)}{\tau K(\theta(\beta, \gamma)+\rho(\gamma))^{2}}\right)\left(T+\frac{e^{-(\theta(\beta, \gamma)+\rho(\gamma)) T}-1}{\theta(\beta, \gamma)+f(\gamma)}\right) \\
& \left.\left.+\frac{1}{2} \frac{\alpha \rho^{2}(\gamma) T^{2}}{\tau K(\theta(\beta, \gamma)+\rho(\gamma))}\right\}+c_{R}\left(I_{o}+R T\right)\right\}
\end{aligned}
$$

Due to extreme nonlinearity and higher dimensional profit function we apply particle swarm optimization (CPSO) algorithm with constriction factor, particle swarm optimization (WPSO) algorithm and genetic algorithm (GA)to solve the problem. In order to apply algorithms in the interval environment we propose the following solution procedure;

\section{Solution Procedure}

1) The objective function in the interval environment consists of two parts $A P_{L}$ and $A P_{R}$. We consider these two functions as two different objective functions.

2) Let $\boldsymbol{y}$ be the decision variable and $\boldsymbol{\sigma}$ be the variable representing the weight for objective function.

3) We define the objective functions as;

$$
F(y, \sigma)=\sigma A P_{L}(y)+(1-\sigma) A P_{R}(y)
$$

4) The decision variable $y$ must satisfy the constraint $A P_{R}<A P_{L}$

5) We run the algorithm to maximize $F(y, 0.5)$ and obtain the optimal value $y^{*}$ such that

\section{Algorithm}

$$
A P_{L}\left(y^{*}\right)<A P_{R}\left(y^{*}\right)
$$


The particle swarm algorithm with constriction factor and genetic algorithm are two direct search methods from two different categories, that is, swarm algorithm and evolutionary algorithm respectively. Using the above solution procedure in section 8 , we obtain the optimal solution of the multi-objective function using both the algorithms and implementing student's t-test we justify that there is no significant difference in the mean of the solution obtained by applying CPSO, WPSO and GA.

\subsection{Genetic Algorithm}

In genetic algorithm, Yang (2015), we basically perform four steps to optimize a function these steps are defined as follows;

Selection: In selection process we select population of finite size randomly from the search boundary. There are various methods of selecting the population; Enlisted selection, Roulette Wheel, Tournament Selection, Rank Selection, Boltzmann Selection etc. In our case we have performed elitist selection method to choose our population.

Crossover:The crossover operation is usually depending on the problem to optimize. Due to the continuous objective function of real decision variables we consider the convex combination of two chromosomes.

Mutation:The purpose of mutation operation is to retard the rate of convergence. The probability of mutation is usually small and included in the algorithm to protect the evolution of solution from being trapped in local optimum. In our GA coding we consider the mutation operation as a minute change in the decision variable.

Stopping Criteria: In this step we provide some valid condition to terminate the iteration process. There are many stopping criteria available although in our GA coding we terminate the algorithm after a certain number of iteration and accept the solution if the variance of the set of global optima is less than $10^{-5}$.

\section{Procedure of Genetic Algorithm}

The individuals are selected for crossover on the basis of fitness probability of each individual and the crossover probability. A set of individuals are selected by elitist selection method. We define crossover probability and mutation probability. Whenever the fitness probability is more than the crossover probability we select the individual for crossover. Similarly, if the fitness probability is less than the mutation probability then we apply the mutation operation on that individual. We repeat the steps until we get a set of global optima in the given search boundary whose variance is less than $10^{-5}$

To perform the soft computing, we assume the following values of the parameters of GA.

Population Size $N=100$

Crossover Probability $c=0.5$

Mutation Probability $m=0.1$

Maximum Iteration Gen $=3000$

\subsection{WPSO Algorithm}

In weighted PSO we attach a weight to the initial velocity of the particle. This weight is often termed as inertial weight which is defined as constant and the value usually ranges between $[0.5,0.9]$ Eberhart\& Shi (2000) and Yang, (2015).

$$
w=\frac{w_{\max }-w_{\min }}{N} i
$$

Where, $N$ is maximum number of iteration, $w_{\max }$ is maximum inertial weight, $w_{\min }$ is minimum inertial weight and $i$ is the iteration number.

Let $x_{j}^{i}$ be the $i^{t h}$ particle at $j^{\text {th }}$ position with initial velocity $u_{j}^{i}$. Then the velocity equation for the $(j+1)^{\text {th }}$ position together with a inertial weight $w$,

$$
u_{j+1}^{i}=w u_{j}^{i}+\operatorname{pr}\left(x_{g}^{*}-x_{j}^{i}\right)+q s\left(x_{p}^{*}-x_{j}^{i}\right)
$$

Where $p$ and $q$ are acceleration coefficients and $r, s \in(0,1)$ are random numbers The $i^{\text {th }}$ particle at $(j+1)^{t h}$ position is given by; 


$$
x_{j+1}^{i}=x_{j}^{i}+u_{j+1}^{i}
$$

Table 16: Pseudo-Algorithm of weighted PSO

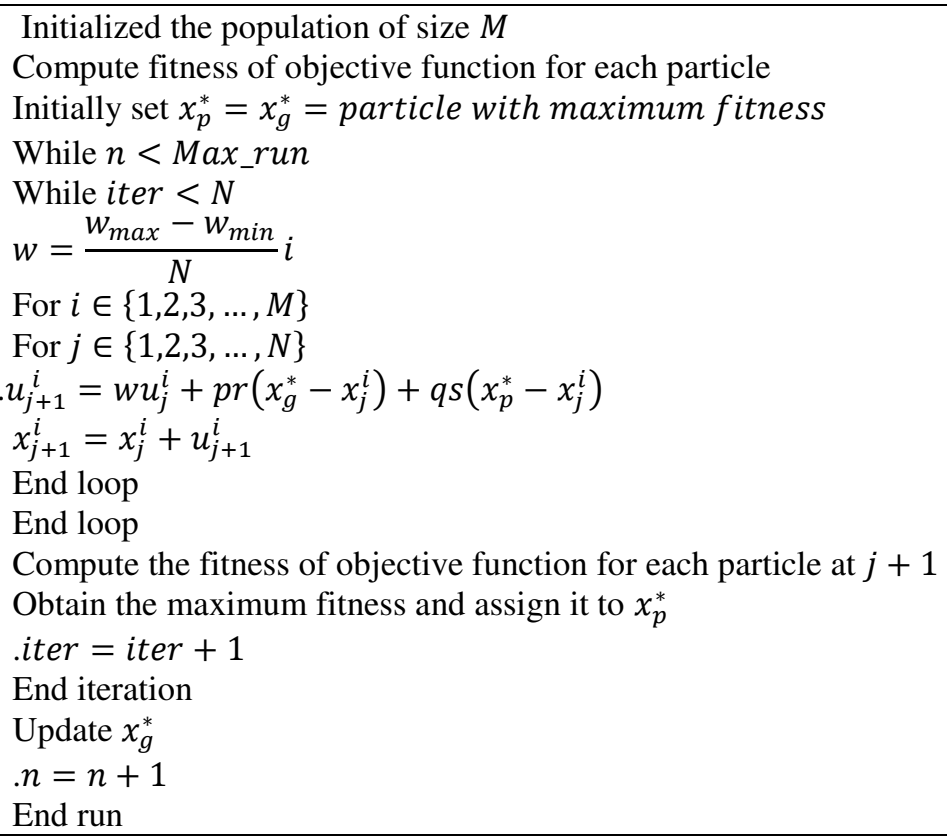

We assume following values of the parameters of WPSO

Population Size $N=100$

Number of Run $\operatorname{Max}_{\text {Run }}=20$

Number of Iteration Max $_{\text {Itr }}=500$

Minimum Inertial Weight $w_{\text {min }}=0.4$

Maximum Inertial Weight $w_{\max }=0.9$

Acceleration Coefficients $c_{1}=2.4$ and $c_{2}=2$

\subsection{CPSO Algorithm}

In CPSO we assign a constant weight to the velocity equationEberhart and Shi (2000). It is an effective measure to control the motion of search particle in the swarm and helps in optimum search of the search boundary. Let $p_{j}^{i}$ be the $i^{\text {th }}$ particle at $j^{\text {th }}$ position with initial velocity $v_{j}^{i}$. Then the velocity equation together with constriction factor $\delta$ for the $(j+1)^{\text {th }}$ position

$$
v_{j+1}^{i}=\delta\left[v_{j}^{i}+a g\left(p_{g}^{*}-p_{j}^{i}\right)+b h\left(p_{p}^{*}-p_{j}^{i}\right)\right]
$$

Where, $a$ and $b$ is known as acceleration coefficient and $g, h \in(0,1)$ are random numbers.

The $i^{\text {th }}$ particle at $(j+1)^{\text {th }}$ position is given by;

The constriction factor is:

$$
p_{j+1}^{i}=p_{j}^{i}+v_{j+1}^{i}
$$

$$
\delta=\frac{2 k}{\left|\varphi-\sqrt{\varphi^{2}-4 \varphi}\right|}
$$

Where, $\varphi=a+b$, is the constriction factor, $k>0$

The $i^{\text {th }}$ particle at $(j+1)^{\text {th }}$ position is given by;

$$
p_{j+1}^{i}=p_{j}^{i}+v_{j+1}^{i}
$$

Table 17: Pseudo-Algorithm of CPSO

Initialized the population of size $P$

Compute fitness of multi-objective function for each $p_{j}^{i}$

Obtain the constriction factor 


Initially set $\quad \delta=\frac{2 k}{\left|\varphi-\sqrt{\varphi^{2}-4 \varphi}\right|}$
\[ p_{t}^{*}=p_{g}^{*}=\text { particle with maximum fitness } \]
While $m<$ max_run
While $i<N$
For $i \in\{1,2,3, \ldots, P\}$
For $j \in\{1,2,3, \ldots, N\}$
\[ v_{j+1}^{i}=\delta\left[v_{j}^{i}+a g\left(p_{g}^{*}-p_{j}^{i}\right)+b h\left(p_{p}^{*}-p_{j}^{i}\right)\right] \]
\[ p_{j+1}^{i}=p_{j}^{i}+v_{j+1}^{i} \]
End loop
End loop
Compute the fitness of multi-objective function for each particle at $j+1$
Obtain the maximum fitness and assign it to $p_{t}^{*}$
$\quad i=i+1$
End iteration
Update $p_{g}^{*}$
End run

We assume following values of the parameters of WPSO

Population Size $N=100$

Number of Run $\operatorname{Max}_{\text {Run }}=20$

Number of Iteration Max $_{\text {Itr }}=500$

Constant $K=1$

Acceleration Coefficients $c_{1}=2.4$ and $c_{2}=2$

\section{Numerical Verification}

In the lack of real data, we assume the following values of the parameters.

Problem (Case I): A vendor selling $I_{0}=1000 \mathrm{lbs}$ at the rate $p=\$ 250$ which deteriorating at a rate $\theta=0.001$ and the rate at which the product emits carbon gases is $\gamma=0.5$ and the effect of carbon emission on demand is $K=0.7$. The carbon emission and deterioration can be controlled by a proper green investment and preservation technology with sensitivity $a=0.15$ and $b=0.13$. There is a constant replenishment of $R=500 \mathrm{lbs}$ per unit time throughout the planning horizon. The initial demand of the product is $d=150 \mathrm{lbs}$ and the price sensitivity is $\alpha=0.2$. The shelf life of the product is $\tau=150$ days. The ordering cost $c_{0}=\$[10000,11000]$, the holding cost of the product is $H=$ $\$[30,35]$, the purchase cost of the product from the source is $c=\$[250,255]$ and the carbon tax is $c_{e}=\$[55,60]$

Table 1: Optimal solution in Case I under Constriction PSO

\begin{tabular}{|c|c|c|c|c|c|c|}
\hline \multirow{2}{*}{ Pattern } & \multirow{2}{*}{$\beta$} & \multirow{2}{*}{$I_{g}$} & \multirow{2}{*}{$T$} & \multicolumn{3}{|c|}{ Profit } \\
\hline & & & & $A P_{R}$ & $A P_{L}$ & Centre \\
\hline I & 671.05 & 919.26 & 78.78 & 1025220.5 & 970056.64 & 997638.59 \\
\hline II & 50.76 & 75.74 & 0.64 & 21250259 & 21233440 & 21241849 \\
\hline III & 53.4 & 77.765 & 0.78 & 20450554 & 20435421 & 20442988 \\
\hline
\end{tabular}

Table 2: Optimal solution in Case I under Weighted PSO

\begin{tabular}{|c|c|c|c|c|c|c|}
\hline \multirow{2}{*}{ Pattern } & \multirow{2}{*}{$\beta$} & \multirow{2}{*}{$I_{g}$} & \multirow{2}{*}{$T$} & \multicolumn{3}{|c|}{ Profit } \\
\hline & & & & $A P_{R}$ & $A P_{L}$ & Centre \\
\hline I & 671.05 & 919.26 & 78.78 & 1025220.5 & 970056.64 & 997638.59 \\
\hline II & 50.76 & 75.74 & 0.64 & 21250259 & 21233440 & 21241849 \\
\hline III & 53.4 & 77.775 & 0.78 & 20450554 & 20435421 & 20442988 \\
\hline
\end{tabular}


Table 3: Optimal solution in Case I under Genetic Algorithm

\begin{tabular}{|c|c|c|c|c|c|c|}
\hline \multirow{2}{*}{ Pattern } & \multirow{2}{*}{$\boldsymbol{\beta}$} & \multirow{2}{*}{$\boldsymbol{g}$} & \multirow{T}{*}{} & \multicolumn{3}{|c|}{ Profit } \\
\cline { 4 - 6 } & & & & $A P_{R}$ & $A P_{L}$ & Centre \\
\hline I & 671.05 & 1250.16 & 78.78 & 1025220.5 & 970056.64 & 997634.49 \\
\hline II & 442.8 & 1525.28 & 0.64 & 21250259 & 21233440 & 21239339 \\
\hline III & 336.54 & 646.98 & 0.78 & 20449470 & 20434350 & 20441910 \\
\hline
\end{tabular}

Table 4: Statistical Analysis of the solution

\begin{tabular}{|c|c|c|c|c|}
\hline \multirow{2}{*}{ Pattern } & $\begin{array}{c}\text { Central } \\
\text { Tendency }\end{array}$ & Constriction PSO & Weighted PSO & $\begin{array}{c}\text { Genetic } \\
\text { Algorithm }\end{array}$ \\
\hline \multirow{4}{*}{ I } & Mean & 997638.59 & 997638.59 & 997634.49 \\
\cline { 2 - 5 } & Median & 997638.59 & 997638.59 & 997634.49 \\
\cline { 2 - 5 } & Variance & $4.574 \times 10^{-20}$ & 5.87836 & $1.109 \times 10^{-18}$ \\
\hline \multirow{3}{*}{ II } & Mean & 21241849 & 21241849 & 21239339 \\
\cline { 2 - 5 } & Median & 21241849 & 21241849 & 21239339 \\
\cline { 2 - 5 } & Variance & 0.4607572 & 0.0010269 & 0.0000538 \\
\hline \multirow{3}{*}{ III } & Mean & 20442988 & 20442988. & 20441910 \\
\cline { 2 - 5 } & Median & 20442988 & 20442988. & 20441910 \\
\cline { 2 - 5 } & Variance & 0.0308171 & $7.18 \times 10^{-8}$ & $2.24 \times 10^{-16}$ \\
\hline
\end{tabular}

Managerial Implications: In the light of above results, the profit is maximum if the amount of carbon emission follows pattern II, although the vendor has to sell the product within 0.64 days which seems difficult except for the case when the vendor is selling products to the industries in bulk. Similar situation can be observed for pattern III. For pattern I, it can be observed that, the planning horizon is more for selling the product is almost 79 days but it reduces the profit in a significant amount which quite obvious because the seller has bear more holding, deterioration and carbon emission cost is the selling period is more. Further the demand of the product is more if the amount of carbon emission is less. Comparing the results obtained for three different search method it is observed that CPSO produce the better results subject to the statistical analysis.

Problem (Case II): A vendor selling $I_{0}=1000 \mathrm{lbs}$ at the rate $p=\$ 250$ which deteriorating at a rate $\theta=0.001$ and the rate of carbon emission is probabilistic and the effect of carbon emission on demand is $K=0.7$. The carbon emission and deterioration can be controlled by a proper green investment and preservation technology with sensitivity $a=0.15$ and $b=0.13$. There is a constant replenishment of $R=500 \mathrm{lbs}$ per unit time throughout the planning horizon. The initial demand of the product is $d=$ $150 \mathrm{lbs}$ and the price sensitivity is $\alpha=0.2$. The shelf life of the product is $\tau=150$ days. The ordering cost $c_{0}=\$[10000,11000]$, the holding cost of the product is $H=\$[30,35]$, the purchase cost of the product from the source is $c=\$[250,255]$ and the carbon tax is $c_{e}=\$[55,60]$. We consider three probability distributions; Uniform, Triangular and Beta.

For Uniform Distribution: $\gamma_{1}=0.5$ and $\gamma_{2}=0.65$. The rate of carbon emission is;

$$
\gamma=\frac{\gamma_{1}+\gamma_{2}}{2}
$$

Table 5: Optimal solution for Uniform Distribution under Constriction PSO

\begin{tabular}{|c|c|c|c|c|c|c|}
\hline \multirow{2}{*}{ Pattern } & \multirow{2}{*}{$\boldsymbol{\beta}$} & \multirow{2}{*}{$\boldsymbol{I}$} & $\boldsymbol{T}$ & \multicolumn{3}{|c|}{ Profit } \\
\cline { 5 - 7 } & & & $A P_{R}$ & $A P_{L}$ & Centre \\
\hline I & 0 & 151.43 & 92.87 & -2429999.2 & -248115.24 & -245557.21 \\
\hline II & 70.83 & 90.23 & 3.16 & 18555324 & 18545868 & 18550596 \\
\hline III & 46.87 & 72.56 & 0.47 & 22997368 & 22977361 & 22987364 \\
\hline
\end{tabular}

Table 6: Optimal solution for Uniform Distribution under Weighted PSO

\begin{tabular}{|c|c|c|c|c|c|c|}
\hline \multirow{2}{*}{ Pattern } & $\boldsymbol{\beta}$ & $\boldsymbol{I}_{\boldsymbol{g}}$ & $\boldsymbol{T}$ & \multicolumn{3}{|c|}{ Profit } \\
\cline { 4 - 5 } & & & $A P_{R}$ & $A P_{L}$ & Centre \\
\hline
\end{tabular}




\begin{tabular}{|c|c|c|c|c|c|c|}
\hline I & 0 & 151.43 & 92.87 & -2429999.2 & -248115.24 & -245557.21 \\
\hline II & 70.83 & 90.23 & 3.16 & 18555324 & 18545868 & 18550596 \\
\hline III & 46.87 & 72.56 & 0.47 & 22997368 & 22977361 & 22987364 \\
\hline
\end{tabular}

Table 7: Optimal solution for Uniform Distribution under Genetic Algorithm

\begin{tabular}{|c|c|c|c|c|c|c|}
\hline \multirow{2}{*}{ Pattern } & \multirow{2}{*}{$\beta$} & \multirow{2}{*}{$I_{g}$} & \multirow{2}{*}{$T$} & \multicolumn{3}{|c|}{ Profit } \\
\hline & & & & $A P_{R}$ & $A P_{L}$ & Centre \\
\hline I & 246.59 & 1104.05 & 92.98 & -243118.5 & -248234.47 & -245570.03 \\
\hline II & 400 & 1941.58 & 3.17 & 18554638 & 18545187 & 18549912 \\
\hline III & 2422.56 & 446.28 & 0.48 & 22991586 & 22971650 & 22981518 \\
\hline
\end{tabular}

Table 8: Statistical Analysis of the solution

\begin{tabular}{|c|c|c|c|c|}
\hline \multirow{2}{*}{ Pattern } & $\begin{array}{c}\text { Central } \\
\text { Tendency }\end{array}$ & Constriction PSO & Weighted PSO & $\begin{array}{c}\text { Genetic } \\
\text { Algorithm }\end{array}$ \\
\hline \multirow{4}{*}{ I } & Mean & -245557.21 & -245557.21 & -245570.03 \\
\cline { 2 - 5 } & Median & -245557.21 & -245557.21 & -245570.03 \\
\cline { 2 - 5 } & Variance & $6.353 \times 10^{-22}$ & $1.271 \times 10^{-21}$ & $8.275 \times 10^{-8}$ \\
\hline \multirow{3}{*}{ II } & Mean & 18550596 & 18550596 & 18549912 \\
\cline { 2 - 5 } & Median & 18550596 & 18550596 & 18549912 \\
\cline { 2 - 5 } & Variance & $1.561 \times 10^{-17}$ & $3.469 \times 10^{-17}$ & $6.869 \times 10^{-16}$ \\
\hline \multirow{3}{*}{ III } & Mean & 22987364 & 22987364 & 22981518 \\
\cline { 2 - 5 } & Median & 22987364 & 22987364 & 22981518 \\
\cline { 2 - 5 } & Variance & $3.296 \times 10^{-17}$ & $1.908 \times 10^{-17}$ & $1.135 \times 10^{-15}$ \\
\hline
\end{tabular}

For Triangular Distribution: $\gamma_{1}=0.5, \gamma_{2}=0.61$ and $\gamma_{3}=0.65$. The rate of carbon emission is

$$
\gamma=\frac{\gamma_{1}+\gamma_{2}+\gamma_{3}}{3}
$$

Table 9: Optimal solution for Triangular Distribution under Constriction PSO

\begin{tabular}{|c|c|c|c|c|c|c|}
\hline \multirow{2}{*}{ Pattern } & \multirow{2}{*}{$\boldsymbol{\beta}$} & \multirow{2}{*}{$I_{g}$} & \multirow{2}{*}{$T$} & \multicolumn{3}{|c|}{ Profit } \\
\hline & & & & $A P_{R}$ & $A P_{L}$ & Centre \\
\hline I & 0 & 151.87 & 98.46 & -244361.81 & -249471.4 & -246916.61 \\
\hline II & 76.02 & 94.33 & 5.03 & 18280036 & 18271171 & 18275604 \\
\hline III & 46.2 & 71.99 & 0.45 & 23391433 & 23370764 & 23381099 \\
\hline
\end{tabular}

Table 10: Optimal solution for Triangular Distribution under Weighted PSO

\begin{tabular}{|c|c|c|c|c|c|c|}
\hline \multirow{2}{*}{ Pattern } & \multirow{2}{*}{$\boldsymbol{\beta}$} & \multirow{2}{*}{$\boldsymbol{I}$} & $\boldsymbol{T}$ & \multicolumn{3}{|c|}{ Profit } \\
\cline { 5 - 7 } & & & $A P_{R}$ & $A P_{L}$ & Centre \\
\hline I & 0 & 151.87 & 98.46 & -244361.81 & -249471.4 & -246916.61 \\
\hline II & 76.02 & 94.33 & 5.03 & 18280036 & 18271171 & 18275604 \\
\hline III & 46.2 & 71.99 & 0.45 & 23391433 & 23370764 & 23381099 \\
\hline
\end{tabular}

Table 11: Optimal solution for Triangular Distribution under Genetic Algorithm

\begin{tabular}{|c|c|c|c|c|c|c|}
\hline \multirow{2}{*}{ Pattern } & \multirow{2}{*}{$\boldsymbol{\beta}$} & \multirow{2}{*}{$\boldsymbol{*}$} & $\boldsymbol{T}$ & \multicolumn{3}{|c|}{ Profit } \\
\cline { 5 - 7 } & & & $A P_{R}$ & $A P_{L}$ & Centre \\
\hline I & 120.36 & 1310.37 & 98.58 & -244374.78 & -249484.24 & -246929.51 \\
\hline II & 372.21 & 917.87 & 5.04 & 18279816 & 18270952 & 18275384 \\
\hline III & 897.29 & 267 & 0.45 & 23389130 & 23368495 & 23378812 \\
\hline
\end{tabular}

Table 12: Statistical Analysis of the solution

\begin{tabular}{|c|c|c|c|c|}
\hline \multirow{2}{*}{ Pattern } & $\begin{array}{c}\text { Central } \\
\text { Tendency }\end{array}$ & Constriction PSO & Weighted PSO & $\begin{array}{c}\text { Genetic } \\
\text { Algorithm }\end{array}$ \\
\hline \multirow{3}{*}{ I } & Mean & -246916.61 & -246916.61 & -246929.51 \\
\cline { 2 - 5 } & Median & -246916.61 & -246916.61 & -246929.51 \\
\cline { 2 - 5 } & Variance & $9.529 \times 10^{-22}$ & $8.47 \times 10^{-22}$ & $6.068 \times 10^{-8}$ \\
\hline II & Mean & 18275604 & 18275604 & 18275384 \\
\hline
\end{tabular}




\begin{tabular}{|c|c|c|c|c|}
\hline \multirow{4}{*}{ III } & Median & 18275604 & 18275604 & 18275384 \\
\cline { 2 - 5 } & Variance & 0.0002086 & 0 & $3.988 \times 10^{-13}$ \\
\hline \multirow{3}{*}{} & Mean & 23381099 & 23381099 & 23378812 \\
\cline { 2 - 5 } & Median & 23381099 & 23381099 & 23378812 \\
\cline { 2 - 5 } & Variance & $1.214 \times 10^{-17}$ & $1.214 \times 10^{-17}$ & $3.504 \times 10^{-16}$ \\
\hline
\end{tabular}

For Beta Distribution: $\gamma_{1}=0.5$ and $\gamma_{2}=0.65$. The rate of carbon emission

$$
\gamma=\frac{\gamma_{1}}{\gamma_{1}+\gamma_{2}}
$$

Table 13: Optimal solution for Beta Distribution under Constriction PSO

\begin{tabular}{|c|c|c|c|c|c|c|}
\hline \multirow{2}{*}{ Pattern } & \multirow{2}{*}{$\boldsymbol{\beta}$} & \multirow{2}{*}{$\boldsymbol{T}$} & $\boldsymbol{T}$ & \multicolumn{3}{|c|}{ Profit } \\
\cline { 4 - 7 } & & & & $A P_{R}$ & $A P_{L}$ & Centre \\
\hline I & 341.79 & 537.47 & 85.16 & 2450694.7 & 2393318.2 & 2423552.1 \\
\hline II & 45.45 & 71.34 & 0.42 & 23863218 & 23841774 & 23852496 \\
\hline III & 72.79 & 91.72 & 3.76 & 18458854 & 18449666 & 18454260 \\
\hline
\end{tabular}

Table 14: Optimal solution for Beta Distribution under Weighted PSO

\begin{tabular}{|c|c|c|c|c|c|c|}
\hline \multirow{2}{*}{ Pattern } & \multirow{2}{*}{$\boldsymbol{\beta}$} & \multirow{2}{*}{$\boldsymbol{T}$} & $\boldsymbol{T}$ & \multicolumn{3}{|c|}{ Profit } \\
\cline { 5 - 7 } & & & $A P_{R}$ & $A P_{L}$ & Centre \\
\hline I & 341.79 & 537.47 & 85.16 & 2450694.7 & 2393318.2 & 2423552.1 \\
\hline II & 45.45 & 71.34 & 0.42 & 23863218 & 23841774 & 23852496 \\
\hline III & 72.79 & 91.72 & 3.76 & 18458854 & 18449666 & 18454260 \\
\hline
\end{tabular}

Table 15: Optimal solution for Beta Distribution under Genetic Algorithm

\begin{tabular}{|c|c|c|c|c|c|c|}
\hline \multirow{2}{*}{ Pattern } & \multirow{2}{*}{$\boldsymbol{\beta}$} & \multirow{2}{*}{$\boldsymbol{T}$} & $\boldsymbol{T}$ & \multicolumn{3}{|c|}{ Profit } \\
\cline { 5 - 7 } & & & $A P_{R}$ & $A P_{L}$ & Centre \\
\hline I & 341.79 & 887.15 & 85.16 & 2452623.8 & 2394472.4 & 2423548.1 \\
\hline II & 2088.3 & 233.87 & 0.427 & 23858051 & 23836674 & 23847363 \\
\hline III & 1011.35 & 1348.43 & 3.77 & 18458274 & 18449089 & 18453681 \\
\hline
\end{tabular}

Table 16: Statistical Analysis of the solution

\begin{tabular}{|c|c|c|c|c|}
\hline \multirow{2}{*}{ Pattern } & $\begin{array}{c}\text { Central } \\
\text { Tendency }\end{array}$ & Constriction PSO & Weighted PSO & $\begin{array}{c}\text { Genetic } \\
\text { Algorithm }\end{array}$ \\
\hline \multirow{3}{*}{ I } & Mean & 2423552.1 & 2423552.1 & 2423548.1 \\
\cline { 2 - 5 } & Median & 2423549.6 & 2423549.6 & 2423548.1 \\
\cline { 2 - 5 } & Variance & 24.44102 & 24.44102 & $1.07 \times 10^{-17}$ \\
\hline \multirow{3}{*}{ II } & Mean & 23852496 & 23852496 & 23847363 \\
\cline { 2 - 5 } & Median & 23852496 & 23852496 & 23847363 \\
\hline \multirow{3}{*}{ III } & Variance & $1.908 \times 10^{-17}$ & $1.908 \times 10^{-17}$ & $5.046 \times 10^{-16}$ \\
\cline { 2 - 5 } & Mean & 18454260 & 18454260 & 18453681 \\
\cline { 2 - 5 } & Median & 18454260 & 18454260 & 18453681 \\
\cline { 2 - 5 } & Variance & 0 & $1.908 \times 10^{-17}$ & 0.0000425 \\
\hline
\end{tabular}

Managerial Implications:In Case II we assumed $\gamma$ to be probabilistic and observed that,

- When $\gamma$ follows uniform and triangular distribution then the supplier must consider the products whose carbon emission follows pattern II and III as for pattern I the average profit is negative. Comparing the profit earn for pattern II and pattern III under uniform and triangular distribution, the manager should select the materials, taking $\gamma$ under triangular distribution because the preservation cost and green investment is less compare to $\gamma$ follows uniform distribution

- For the products whose rate if carbon emission follows pattern I, it is suggested that, the manager should consider the beta distribution for analysing and decision making purposes. Further the manager could select the product whose carbon emission follows pattern II, because the average profit is maximum for pattern II under beta distribution. 
Problem (Case III): A vendor selling $I_{0}=1000 \mathrm{lbs}$ with selling price $p$ probabilistic which is deteriorating at a rate $\theta=0.001$ and the rate at which the product emits carbon gases is $\gamma=0.5$ and the effect of carbon emission on demand is $K=0.7$. The carbon emission and deterioration can be controlled by a proper green investment and preservation technology with sensitivity $a=0.15$ and $b=$ 0.13. There is a constant replenishment of $R=500 \mathrm{lbs}$ per unit time throughout the planning horizon. The initial demand of the product is $d=150 \mathrm{lbs}$ and the price sensitivity is $\alpha=0.2$. The shelf life of the product is $\tau=150$ days. The ordering cost $c_{0}=\$[10000,11000]$, the holding cost of the product is $H=\$[30,35]$, the purchase cost of the product from the source is $c=\$[250,255]$ and the carbon $\operatorname{tax}$ is $c_{e}=\$[55,60]$

For Uniform Distribution: $p_{1}=250$ and $p_{2}=375$. The rate of carbon emission is;

$$
p=\frac{p_{1}+p_{2}}{2}
$$

Table 17: Optimal solution for Uniform Distribution under Constriction PSO

\begin{tabular}{|c|c|c|c|c|c|c|}
\hline \multirow{2}{*}{ Pattern } & \multirow{2}{*}{$\boldsymbol{\beta}$} & \multirow{2}{*}{$\boldsymbol{T}$} & $\boldsymbol{T}$ & \multicolumn{3}{|c|}{ Profit } \\
\cline { 5 - 7 } & & & $A P_{R}$ & $A P_{L}$ & Centre \\
\hline I & 671.25 & 919.7 & 81.33 & 1408539.2 & 1352019.6 & 1380279.4 \\
\hline II & 50.61 & 74.8 & 0.56 & 26919052 & 26900983 & 26910018 \\
\hline III & 53.24 & 76.82 & 0.68 & 25882807 & 25866636 & 25874722 \\
\hline
\end{tabular}

Table 18: Optimal solution for Uniform Distribution under Weighted PSO

\begin{tabular}{|c|c|c|c|c|c|c|}
\hline \multirow{2}{*}{ Pattern } & \multirow{2}{*}{$\boldsymbol{\beta}$} & \multirow{2}{*}{$\boldsymbol{*}$} & $\boldsymbol{T}$ & \multicolumn{3}{|c|}{ Profit } \\
\cline { 5 - 7 } & & & $A P_{R}$ & $A P_{L}$ & Centre \\
\hline I & 671.25 & 919.7 & 81.33 & 1408539.2 & 1352019.6 & 1380279.4 \\
\hline II & 50.61 & 74.8 & 0.56 & 26919052 & 26900983 & 26910018 \\
\hline III & 53.24 & 76.82 & 0.68 & 25882807 & 25866636 & 25874722 \\
\hline
\end{tabular}

Table 19: Optimal solution for Uniform Distribution under Genetic Algorithm

\begin{tabular}{|c|c|c|c|c|c|c|}
\hline \multirow{2}{*}{ Pattern } & \multirow{2}{*}{$\boldsymbol{\beta}$} & \multirow{2}{*}{$\boldsymbol{T}$} & $\boldsymbol{T}$ & \multicolumn{3}{|c|}{ Profit } \\
\cline { 5 - 7 } & & & & $A P_{R}$ & $A P_{L}$ & Centre \\
\hline I & 671.25 & 1103.26 & 81.33 & 1408537 & 1352017.4 & 1380277.2 \\
\hline II & 94.9 & 771.92 & 0.56 & 26917754 & 26899699 & 26908726 \\
\hline III & 1027.02 & 1406.42 & 0.69 & 25879455 & 25863329 & 25871392 \\
\hline
\end{tabular}

Table 20: Statistical Analysis of the solution

\begin{tabular}{|c|c|c|c|c|}
\hline \multirow{2}{*}{ Pattern } & $\begin{array}{c}\text { Central } \\
\text { Tendency }\end{array}$ & Constriction PSO & Weighted PSO & $\begin{array}{c}\text { Genetic } \\
\text { Algorithm }\end{array}$ \\
\hline \multirow{4}{*}{ I } & Mean & 1380279.4 & 1380279.4 & 1380277.2 \\
\cline { 2 - 5 } & Median & 1380279.4 & 1380279.4 & 1380277.2 \\
\cline { 2 - 5 } & Variance & $1.355 \times 10^{-20}$ & 13.76905 & $2.683 \times 10^{-18}$ \\
\hline \multirow{3}{*}{ II } & Mean & 26910018 & 26910018 & 26908726 \\
\cline { 2 - 5 } & Median & 26910018 & 26910018 & 26908726 \\
\cline { 2 - 5 } & Variance & $1.567 \times 10^{-17}$ & $1.0 \times 10^{-17}$ & $8.971 \times 10^{-16}$ \\
\hline \multirow{3}{*}{ III } & Mean & 25874722 & 25874722 & 25871392 \\
\cline { 2 - 5 } & Median & 25874722 & 25874722 & 25871392 \\
\cline { 2 - 5 } & Variance & $8.674 \times 10^{-18}$ & $1.735 \times 10^{-17}$ & $2.424 \times 10^{-11}$ \\
\hline
\end{tabular}

For Triangular Distribution: $p_{1}=250, p_{2}=300$ and $p_{3}=375$. The rate of carbon emission is

$$
p=\frac{p_{1}+p_{2}+p_{3}}{3}
$$

\begin{tabular}{|c|c|c|c|c|c|c|}
\hline \multirow{2}{*}{ Pattern } & \multirow{2}{*}{$\beta$} & \multirow{2}{*}{$I_{g}$} & \multirow{2}{*}{$T$} & \multicolumn{3}{|c|}{ Profit } \\
\hline & & & & $A P_{R}$ & $A P_{L}$ & Centre \\
\hline I & 671.24 & 919.68 & 81.19 & 1382939.3 & 1326493.1 & 1354716.2 \\
\hline II & 50.62 & 74.86 & 0.57 & 26538178 & 26520188 & 26529183 \\
\hline III & 53.25 & 76.87 & 0.69 & 25517974 & 25501869 & 25509921 \\
\hline
\end{tabular}

Table 21: Optimal solution for Triangular Distribution under Constriction PSO 
Table 22: Optimal solution for Triangular Distribution under Weighted PSO

\begin{tabular}{|c|c|c|c|c|c|c|}
\hline \multirow{2}{*}{ Pattern } & \multirow{2}{*}{} & \multirow{2}{*}{} & $\boldsymbol{T}$ & \multicolumn{3}{|c|}{ Profit } \\
\cline { 5 - 7 } & & & & $A P_{R}$ & $A P_{L}$ & Centre \\
\hline I & 671.24 & 919.68 & 81.19 & 1382939.3 & 1326493.1 & 1354716.2 \\
\hline II & 50.62 & 74.86 & 0.57 & 26538178 & 26520188 & 26529183 \\
\hline III & 53.25 & 76.87 & 0.69 & 25517974 & 25501869 & 25509921 \\
\hline
\end{tabular}

Table 23: Optimal solution for Triangular Distribution under Genetic Algorithm

\begin{tabular}{|c|c|c|c|c|c|c|}
\hline \multirow{2}{*}{ Pattern } & \multirow{2}{*}{$\boldsymbol{\beta}$} & \multirow{2}{*}{$\boldsymbol{I}$} & $\boldsymbol{T}$ & \multicolumn{3}{|c|}{ Profit } \\
\cline { 5 - 7 } & & & $A P_{R}$ & $A P_{L}$ & Centre \\
\hline I & 671.24 & 906.47 & 81.19 & 1382939.1 & 1326492.8 & 1354715.9 \\
\hline II & 2421.9 & 445.61 & 0.57 & 26533349 & 26515420 & 26524384 \\
\hline III & 2739.4 & 1464.2 & 0.7 & 25512086 & 25496056 & 25504071 \\
\hline
\end{tabular}

Table 24: Statistical Analysis of the solution

\begin{tabular}{|c|c|c|c|c|}
\hline \multirow{2}{*}{ Pattern } & $\begin{array}{c}\text { Central } \\
\text { Tendency }\end{array}$ & Constriction PSO & Weighted PSO & $\begin{array}{c}\text { Genetic } \\
\text { Algorithm }\end{array}$ \\
\hline \multirow{3}{*}{ I } & Mean & 1354716.2 & 1354716.2 & 1354715.9 \\
\cline { 2 - 5 } & Median & 1354716.2 & 1354716.2 & 1354715.9 \\
\cline { 2 - 5 } & Variance & 5.5267234 & 0.0000254 & $1.971 \times 10^{-18}$ \\
\hline \multirow{3}{*}{ II } & Mean & 26529183 & 26529183 & 26524384 \\
\cline { 2 - 5 } & Median & 26529183 & 26529183 & 26524384 \\
\cline { 2 - 5 } & Variance & $2.082 \times 10^{-17}$ & $2.082 \times 10^{-17}$ & 0.0000877 \\
\hline \multirow{3}{*}{ III } & Mean & 25509921 & 25509921 & 25504071 \\
\cline { 2 - 5 } & Median & 25509921 & 25509921 & 25504071 \\
\cline { 2 - 5 } & Variance & $6.939 \times 10^{-18}$ & $6.939 \times 10^{-18}$ & $2.019 \times 10^{-15}$ \\
\hline
\end{tabular}

For Gamma Distribution: $r=14.7$ and $\rho=2.1$. The rate of carbon emission

$$
p=r^{\rho}
$$

Table 25: Optimal solution for Gamma Distribution under Constriction PSO

\begin{tabular}{|c|c|c|c|c|c|c|}
\hline \multirow{2}{*}{ Pattern } & \multirow{2}{*}{$\boldsymbol{\beta}$} & \multirow{2}{*}{$\boldsymbol{T}$} & \multirow{2}{|c|}{ Profit } \\
\cline { 4 - 6 } & & 919.52 & 80.26 & 1225737.3 & 1169788.7 & 1197763 \\
\hline I & 671.16 & 75.22 & 0.59 & 24206660 & 24189169 & 24197914 \\
\hline II & 50.68 & 77.24 & 0.72 & 23284197 & 23268506 & 23276351 \\
\hline III & 53.31 & &
\end{tabular}

Table 26: Optimal solution for Gamma Distribution under Weighted PSO

\begin{tabular}{|c|c|c|c|c|c|c|}
\hline \multirow{2}{*}{ Pattern } & \multirow{\beta}{*}{} & \multirow{2}{*}{$\boldsymbol{T}$} & $\boldsymbol{T}$ & \multicolumn{3}{|c|}{ Profit } \\
\cline { 4 - 7 } & & & & $A P_{R}$ & $A P_{L}$ & Centre \\
\hline I & 671.16 & 919.52 & 80.26 & 1225737.3 & 1169788.7 & 1197763 \\
\hline II & 50.68 & 75.22 & 0.59 & 24206660 & 24189169 & 24197914 \\
\hline III & 53.31 & 77.24 & 0.72 & 23284197 & 23268506 & 23276351 \\
\hline
\end{tabular}

Table 27: Optimal solution for Gamma Distribution under Genetic Algorithm

\begin{tabular}{|c|c|c|c|c|c|c|}
\hline \multirow{2}{*}{ Pattern } & \multirow{2}{*}{$\beta$} & \multirow{2}{*}{$I_{g}$} & \multirow{2}{*}{$T$} & \multicolumn{3}{|c|}{ Profit } \\
\hline & & & & $A P_{R}$ & $A P_{L}$ & Centre \\
\hline I & 671.16 & 1177.38 & 80.26 & 1225734.1 & 1169785.7 & 1197759.9 \\
\hline II & 1523.52 & 427.54 & 0.6 & 24203600 & 24186149 & 24194875 \\
\hline III & 471.6 & 185 & 0.72 & 23283486 & 23267805 & 23275645 \\
\hline
\end{tabular}

Table 28: Statistical Analysis of the solution

\begin{tabular}{|c|c|c|c|c|}
\hline Pattern & $\begin{array}{c}\text { Central } \\
\text { Tendency }\end{array}$ & Constriction PSO & Weighted PSO & $\begin{array}{c}\text { Genetic } \\
\text { Algorithm }\end{array}$ \\
\hline I & Mean & 1197763 & 1197763 & 1197759.9 \\
\hline
\end{tabular}




\begin{tabular}{|c|c|c|c|c|}
\hline \multirow{4}{*}{ II } & Median & 1197763 & 1197763 & 1197759.9 \\
\cline { 2 - 5 } & Variance & $4.066 \times 10^{-20}$ & $1.256 \times 10^{-12}$ & $7.88 \times 10^{-18}$ \\
\hline \multirow{3}{*}{ III } & Mean & 24197914 & 24197914 & 24194875 \\
\cline { 2 - 5 } & Median & 24197914 & 24197914 & 24194875 \\
\cline { 2 - 5 } & Variance & $6.939 \times 10^{-18}$ & $2.887 \times 10^{-17}$ & $2.243 \times 10^{-16}$ \\
\hline & Mean & 23276351 & 23276351 & 23275645 \\
\cline { 2 - 5 } & Median & 23276351 & 23276351 & 23275645 \\
\cline { 2 - 5 } & Variance & $5.204 \times 10^{-18}$ & $2.881 \times 10^{-16}$ & $6.869 \times 10^{-16}$ \\
\hline
\end{tabular}

Managerial Implications:The following observation have been made in Case III;

- For all the probabilistic distributions, the products with carbon emission pattern II can produce maximum average profit and simultaneously the preservation cost and green investment is less than pattern I and pattern II.

- $\quad$ For probabilistic price under uniform distribution shows maximum profit.

\section{Sensitivity Analysis}

We perform sensitivity of analysis of the cost parameters of in all the cases. Let $N$ be any parameter then the change in the parameter is considered by the formula $N \rightarrow N+N * r$ where, $r \in$ $\{-0.2,-0.1,0.1,0.2\}$. Since profit is maximum in Case I for pattern II. So we perform the sensitivity analysis of the parameters under pattern II,

Table 29: Sensitivity Analysis of Parameters in Case I for Pattern II

\begin{tabular}{|c|c|c|c|c|c|}
\hline Parameter & $\%$ Change & $\beta$ & $I_{g}$ & $T$ & Profit \\
\hline \multirow{4}{*}{$\boldsymbol{H}$} & 0.2 & 50.76 & 75.73 & 0.63 & 21235489 \\
\hline & 0.1 & 50.76 & 75.74 & 0.64 & 21238669 \\
\hline & -0.1 & 50.76 & 75.74 & 0.64 & 21245029 \\
\hline & -0.2 & 50.76 & 75.74 & 0.64 & 21248210 \\
\hline \multirow{4}{*}{$c_{e}$} & 0.2 & 50.76 & 77.14 & 0.64 & 21241847 \\
\hline & 0.1 & 50.76 & 76.47 & 0.64 & 21241848 \\
\hline & -0.1 & 50.76 & 74.93 & 0.64 & 21241851 \\
\hline & -0.2 & 50.76 & 74.02 & 0.64 & 21241852 \\
\hline \multirow{4}{*}{$\boldsymbol{c}$} & 0.2 & 52 & 76.47 & 0.7 & 21141107 \\
\hline & 0.1 & 51.43 & 76.12 & 0.67 & 21190561 \\
\hline & -0.1 & 50 & 75.31 & 0.6 & 21295244 \\
\hline & -0.2 & 49.2 & 74.86 & 0.57 & 21351091 \\
\hline \multirow{4}{*}{$p$} & 0.2 & 50.6 & 74.98 & 0.58 & 25768768 \\
\hline & 0.1 & 50.7 & 75.34 & 0.6 & 23497631 \\
\hline & -0.1 & 50.83 & 76.18 & 0.68 & 19001730 \\
\hline & -0.2 & 50.91 & 76.68 & 0.72 & 16777668 \\
\hline \multirow{4}{*}{$\tau$} & 0.2 & 50.86 & 75.06 & 0.58 & 25610861 \\
\hline & 0.1 & 50.81 & 75.39 & 0.6 & 23425578 \\
\hline & -0.1 & 50.68 & 76.12 & 0.67 & 19059881 \\
\hline & -0.2 & 50.6 & 76.54 & 0.71 & 16879928 \\
\hline \multirow{4}{*}{$\gamma$} & 0.2 & 79.6 & 97.49 & 6.96 & 18019180 \\
\hline & 0.1 & 59.49 & 82.17 & 1.24 & 19348543 \\
\hline & -0.1 & 46.43 & 72.19 & 0.46 & 23236067 \\
\hline & -0.2 & 43.52 & 69.62 & 0.37 & 25273051 \\
\hline \multirow{4}{*}{$\boldsymbol{\theta}$} & 0.2 & 51.97 & 75.74 & 0.64 & 21241847 \\
\hline & 0.1 & 51.4 & 75.74 & 0.64 & 21241848 \\
\hline & -0.1 & 50.05 & 75.74 & 0.64 & 21241850 \\
\hline & -0.2 & 49.47 & 75.73 & 0.67 & 21241852 \\
\hline
\end{tabular}

\section{Interpretation of Sensitivity Analysis}

1) Holding cost $(H)$ : Profit increases with the decrease in holding cost. Not much effect is observed in the decision variables with the change in holding cost.

2) Carbon emission cost $\left(c_{e}\right)$ : Profit increases with the decrease in carbon emission cost. A mild increase in green investment is observed with the increase in carbon emission cost. 
3) Purchase cost $(c)$ : Profit increases with the decrease in purchase cost. All the decision variables, $\beta, I_{g}$ and $T$ decreases with the decrease in purchase cost.

4) Selling Price $(p)$ : Profit increases with the increase in selling price. Planning horizon increases with the decrease in selling price.

5) Shelf-life $(\tau)$ : Profit decreases with the decrease in shelf-life. A little increase in the planning horizon is observed when shelf-life decreases.

6) Rate of Carbon Emission $(\gamma)$ : Profit decreases with the increase in the rate of carbon emission. Moreover, $\beta, I_{g}$ and $T$ increases with the increase in $\gamma$.

7) Rate of Deterioration $(\theta)$ : A mild decrease in the profit is observed with the increase in the rate of deterioration further, preservation cost increases with the increase in the rate of carbon emission.

\section{Conclusion}

This is a single product inventory model to provide a decision making process for selecting right product to sale in an open market. The products considered in this model are perishable in nature and has different rate/ amount of carbon emission. Further the production industries select those products for manufacturing that has low rate/amount of carbon emission so that the burden of carbon tax on overall production can be minimize. Thus the amount of carbon emission has an effect on the demand of the product. Moreover, the selling price reduces with time and eventually diminish so the product must be sold within the finite shelf-life. Therefore, both shelf-life and carbon emission affects the demand of a product. In our present paper we consider three patterns of carbon emission and analyse the profit earns by the seller, also we have computed optimum preservation cost and green investments to reduce deterioration and carbon emission. We divide the problem in three different cases;

In Case I, we have studied the effective preservation cost and green investment to maximize the profit. It is observed that, the product under pattern II emission can generate maximum profit for the supplier.

In Case II, we assume the rate of carbon emission probabilistic and follow uniform, triangular and beta distribution. We observed that, when rate of carbon emission follows beta distribution then supplier can earn maximum profit.

In Case III, we consider the selling price is probabilistic and follow uniform, triangular and gamma distribution. We observed that, supplier can generate maximum profit under pattern II when price follow uniform distribution.

We perform sensitivity analysis and noted that, holding cost, carbon emission cost, purchase cost, rate of carbon emission, shelf-life are sensitive parameters and the supplier should select the product for sale subject to the effect of parameters on the profit function as given in Table 29.

In our present paper we propose a solution procedure and apply Genetic Algorithm (GA), Weighted PSO (WPSO) and Constriction PSO (CPSO) to solve the profit function for optimization. Form the results and statistical analysis given in Table 1-28 we conclude that constriction PSO provide better results as compare to the GA and WPSO.

This is an extension in the literature on inventory modelling that studies the effect of emission and shelf-life on the demand of a product and the profit earn by the supplier under both deterministic and stochastic environments which is not reported in the literature earlier as per the authors knowledge is concern. Present model can be further extended to study the effect trade credit on the demand and profit, and it would be an important study as large vendors and suppliers start their business in credit system.

\section{Compliance with Ethical Standards}

Conflict of Interest: All the authors declare that they have no conflict of interest.

Ethical approval: There is no involvement of animal Funding details: Not applicable. 


\section{Reference}

Aliabadi, L., Yazdanparast, R., Nasiri, M. M., An inventory model for non-instantaneous deteriorating items with credit period and carbon emission sensitive demand: a sigmoidal geometric programming approach, Int. J. Manag. Sci. Eng. Manag., 2018, 14, 124-136.

Arikan, E., Jammernegg, W., (2014). The single period inventory model under dual sourcing and product carbon footprint constraint, Int. J. Prod. Econ., 2014, 157, 15-23.

Benjaafar, S., Li, Y., Daskin, M., Carbon footprint and the management of supply chains: insights from simple models, IEEE Trans. Autom. Sci. Eng., 2013, 10, 99-116

Christata, B. R., Daryanto, Y., (2020). EOQ Inventory Model with Carbon Emission Consideration: A Literature Review, Proceeding on International Conference of Science Management Art Research Technology, Vol 1, No. 1, pp.19-25

De-la-Cruz-Marquez, C. G., Cardenas-Barron, L. E., Mandal D., (2021). An Inventory Model for Growing Items with Imperfect Quality When the Demand Is Price Sensitive under Carbon Emissions and Shortages, Mathematical Problems in Engineering, Hindawi, Vol. 2021, Article ID 6649048, pp.1-23.

Dutta, T. K., (2017). Effect of Green Technology Investment on a Production-Investment System with Carbon Tax, Advances in Operations Research, Hindawi, Vol. 2017, Article ID 4834839, pp.1-12

Dutta, T. K., Nath, P., Choudhury, K. D., (2019). A hybrid carbon policy inventory model with emission source-based green investments, Opsearch, https://doi.org/10.1007/s12597-019- 00430y.

Eberhart, R. C., Shi, Y., (2000). Comparing inertial weights and constriction factor in particle swarm optimization, DOI:10.1109/CEC.2000.870279

Hovelaque, V, Bironnean, L., (2015). The carbon-constrained EOQ model with carbon emission dependent demand. International Journal of Production Economics, Elsevier, 2015, 164, pp.285291

Lu. Chi-jie, Lee, Tian-Shyug, Gu, Ming, Yang, Chih-Te, (2020). A multistage sustainable production inventory model with carbon emission reduction and price dependent demand under stackelberg game, Applied Science, Vol. 10, No. 4878, pp.1-23. doi:10.3390/app10144878

Macias-Lopez, A., Cardenas-Barron, L. E., Peimbert-Garcia, R. E., Mandal, B., (2021). An Inventory Model for Perishable Items with Price-, Stock-, and Time-Dependent Demand Rate considering Shelf-Life and Nonlinear Holding Costs, Mathematical Problems in Engineering, Hindawi, Vol. 2021, Article ID 6630938, pp.1-36

Palanivel, M., Priyan, S., \&Uthayakumar, R., (2015). An inventory model with finite replenishment, probabilistic deterioration and permissible delay in payments.Journal of Management Analytics, 2(3), 254-279.

Ritha, W., Poongodisathiya, S., (2018). Optimal Green Inventory Model to Regulate Eco-friendly Environment, Int. J. of Res. in Engg and Tech., Vol. 4, Issue 5, pp.13-16

Saha, S., Nielsen, I., Sana, S. S., (2021). Effect of optimal subsidy rate and strategic behaviour of supply chain members under competition on green product retailing, Mathematical Problems in Engineering, Hindawi, Vol. 2021, Article ID 6661103, pp.1-23.

Sarkar, Biswajit, (2013). A production-inventory model with probabilistic deterioration in two-echelon supply chain management, Applied Mathematical Modelling, 37, 3138-3151.

Sarkar, M., \& Sarkar, B., (2013). An economic manufacturing quantity model with probabilistic deterioration in a production system. Economic Modelling, 31, 245-252.

Sarkar, B., Ahmed, W., Choi, Seok-Beom, Tayyab, M., (2018). Sustainable inventory management for environment impact through partial backordering and multi-trade-credit-period, Sustainability, Vol. 10, No. 4761, pp.1-28, doi:10.3390/su10124761 
Singh, S. R., Gupta, Vandana, Gupta, Preety, (2013). EOQ Model with Volume Agility, Variable Demand Rate, Weibull Deterioration Rate and Inflation, International Journal of Computer Applications, 72(23), 1-7

Tang, Z., Liu, X., Wang, Y., (2020). Integrated Optimization of Sustainable Transportation and Inventory with Multiplayer Dynamic Game under Carbon, Mathematical Problems in Engineering, Hindawim Vol. 2020, Article ID 4948383, pp.1-16

Yang, Xin-She, (2015). Introduction to computational mathematics, World Scientific Publishing, $2^{\text {nd }}$ Edition, 313-316. 